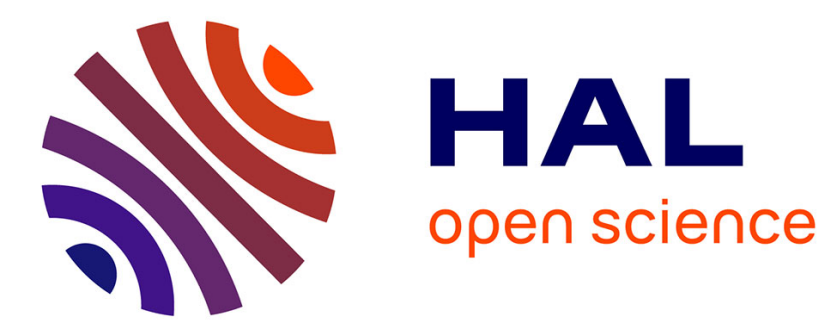

\title{
Impurity-related vibrational modes in a pentacene crystal
}

\author{
G. Volonakis, L. Tsetseris, S. Logothetidis
}

\section{To cite this version:}

G. Volonakis, L. Tsetseris, S. Logothetidis. Impurity-related vibrational modes in a pentacene crystal. European Physical Journal: Applied Physics, 2011, 55 (2), 10.1051/epjap/2011100423 . hal00723600

\section{HAL Id: hal-00723600 \\ https://hal.science/hal-00723600}

Submitted on 11 Aug 2012

HAL is a multi-disciplinary open access archive for the deposit and dissemination of scientific research documents, whether they are published or not. The documents may come from teaching and research institutions in France or abroad, or from public or private research centers.
L'archive ouverte pluridisciplinaire HAL, est destinée au dépôt et à la diffusion de documents scientifiques de niveau recherche, publiés ou non, émanant des établissements d'enseignement et de recherche français ou étrangers, des laboratoires publics ou privés. 


\title{
Impurity-related vibrational modes in a pentacene crystal
}

\author{
G. Volonakis ${ }^{1, a}$, L. Tsetseris ${ }^{2,3}$, and S. Logothetidis ${ }^{1}$ \\ 1Department of Physics, Aristotle University of Thessaloniki, Thessaloniki, Greece \\ 2Department of Physics, National Technical University of Athens, Athens, Greece \\ 3Department of Physics and Astronomy, Vanderbilt University, Nashville, TN, USA \\ a Corresponding author, phone number: +30-2310-998239, email:gvolo@physics.auth.gr
}

\begin{abstract}
The presence of impurities in the molecular crystals of organic semiconductors is a key limiting factor for the performance of related electronic devices. For this reason, the atomic-scale details of impurity incorporation are important elements for modeling and optimization of organic electronic systems. In this article, we use first-principles density-functional theory calculations to describe the vibrational spectrum of typical impurity culprits in the prototype organic semiconductor pentacene. First, we validate the computational approach by comparing results on vibrational modes of impurity-free pentacene with available theoretical and experimental data. We then analyze the effect of oxygen, water, and hydrogen impurities on the modes of pentacene crystals. The results identify distinct impurity-related features which can help understand the evolution of impurities in pentacene samples.
\end{abstract}

\section{Introduction}

The degradation of organic electronic systems due to the presence of defects and chemical impurities has long been recognized as one of the most important hindering factors for the development of associated electronic devices [1-3]. For example, experimental data on oxygen insertion and reactions in various organic semiconductors show that these processes create traps for charge carriers, limiting mobility and degrading transport characteristics [4-9]. Theoretical studies have probed the effect of impurities on the electronic properties of organic materials, and, in certain cases, found agreement with available experimental data. Examples include the creation of carrier traps due to oxygen incorporation in pentacene, rubrene, or $\mathrm{C}_{60}$ fullerite crystals [10-14]. However the existence of a large number of possible impurity configurations creates the need to test the atomic-scale structural details of these configurations against pertinent experimental data. Specifically, comparison between theoretical and experimental Raman or infrared spectroscopic data can enable the identification of impurity structures and ultimately lead to methods that restrict impurity-related degradation phenomena.

In this article, we use quantum-mechanical first-principles calculations to obtain the vibrational modes of oxygen, water, and hydrogen-related impurities in pentacene, a widely used small-molecule organic semiconductor. Previous theoretical and experimental studies [15-18] have probed the vibrational modes of pristine pentacene, but results on related impurity effects remain missing. These results are described below for a number of modes that differ in the chemical form and the position of impurities in a pentacene crystal. 


\section{Methodology}

The calculations employed the densityfunctional theory (DFT) code VASP [19]. Ultrasoft pseudopotentionals were used to describe the interactions between the valence electrons and ionic cores, [20] while the exchange and correlation interactions of the valence electrons were described through a local-density approximation (LDA) [21] functional. The energy cutoff was set at 400 $\mathrm{eV}$. For the calculations of the vibrational modes for pristine pentacene crystal, we used a unit cell containing 2 molecules as proposed by Campbell et al. $[22,23]$ and a $2 \times 2 \times 2$ k-point grid. Impurity calculations employed $2 \times 2 \times 1$ supercells in terms of the unit cell, containing 8 pentacene molecules per supercell and the $\Gamma$ point for k-point sampling. Vibrational modes that were calculated with a finer $2 \times 2 \times 2 \mathrm{k}$-grid differ from those obtained with $\Gamma$ point sampling by less than $3 \mathrm{~cm}^{-1}$. Vibrational modes were obtained as eigenvalues of the dynamical matrix, and included two-point finite differences with displacements away from the equilibrium positions of atoms. Convergence was confirmed both for more displacements and different step sizes.

\section{Results and discussion}

\subsection{Impurity-free pentacene}

Based on the experimental data on the socalled solution phase [22,23], the lattice parameters for crystalline unit cell were set at $\mathrm{a}=6.06 \AA, \quad \mathrm{b}=7.9 \AA \mathrm{\AA}, \mathrm{c}=14.88 \AA \mathrm{A}, \alpha=96.77 \mathrm{o}$, $\beta=100.54^{\circ}$ and $\gamma=94.2^{\circ}$. Optimization of the structure of pentacene molecules within a unit-cell of the crystal yielded $\mathrm{C}-\mathrm{C}$ bond lengths in the range of $1.36 \AA$ to $1.44 \AA$. These bond lengths are in excellent agreement with previous $a b$ initio (1.37-1.46 $\AA$ ) and experimental studies (1.35-1.45 $\mathrm{A})[16,22]$.

Before analyzing impurity-related effects, let us discuss results on selected vibrational modes of an isolated impurity-free pentacene molecule. The two modes shown in Figs. 1a-b have frequencies of $1170 \mathrm{~cm}^{-1}$ and $1136 \mathrm{~cm}^{-1}$, respectively, and they correspond to vibrations of $\mathrm{H}$-atoms within the molecular plane. The corresponding frequency values in previous theoretical (experimental) studies were 1223 (1178) and 1194 (1158) $\mathrm{cm}^{-1}$ [15]. The Raman-active mode depicted in Fig. 1c, on the other hand, has a frequency of $265 \mathrm{~cm}^{-1}$, while previous calculated and measured values placed this eigenvalue at 263 and 266 $\mathrm{cm}^{-1}[16]$, respectively.

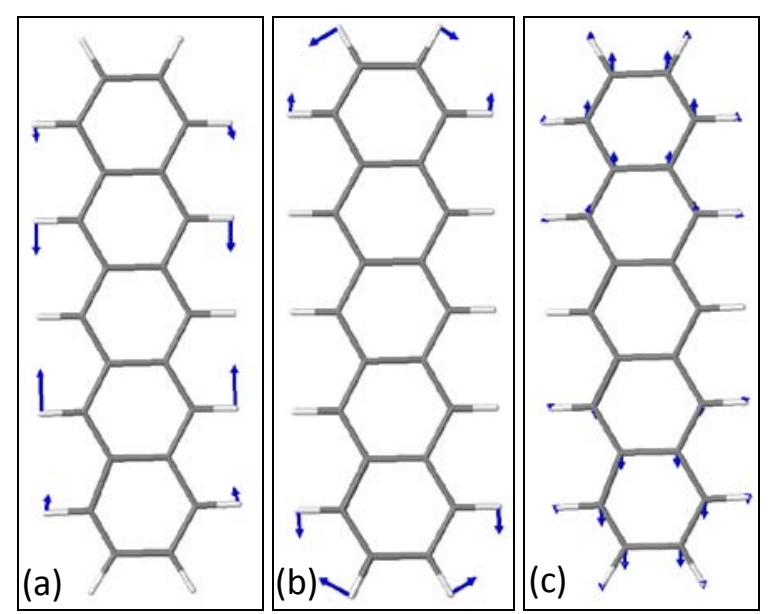

Figure 1. Selected vibrational modes for an isolated pentacene molecule with frequencies 1170 (a), 1136 (b) and $265 \mathrm{~cm}^{-1}$ (c)

The close agreement between our results and those of previous studies reinforce the validity of the computational approach employed here for the analysis of impurity effects.

\subsection{0xygen Impurities}

Total-energy DFT calculations [10] on $\mathrm{O}_{2}$ insertion in pentacene crystals identified two dissociated forms of pairs of $\mathrm{O}$ atoms as the most stable configurations. These configurations include the pair of epoxy bridges shown in Fig. 2(a) $\left(\mathrm{O}_{\mathrm{I}}\right)$ and intermolecular bridge structure of Fig. 2(b) $\left(\mathrm{O}_{\mathrm{II}}\right)$. Moreover, since the dissociation energy [10] of oxygen pairs to individual 0 impurities is very small $(\sim 0.1 \mathrm{eV})$, the atomic 0 structures depicted in Fig. 1c $\left(\mathrm{O}_{\text {III }}\right)$ and Fig. $1 \mathrm{~d}\left(\mathrm{O}_{\mathrm{IV}}\right)$ are as energetically favorable as the geometries $\mathrm{O}_{\mathrm{I}}$ and $\mathrm{O}_{\text {II. }}$ Oxygen impurities in these 
configurations cause displacements of neighboring atoms off their equilibrium positions. In particular removal of the 0 impurities causes relaxation of up to 0.48 , $0.57,0.74$ and $0.72 \AA$ for vicinal atoms in structures $\mathrm{O}_{\mathrm{I}}, \mathrm{O}_{\mathrm{II}}, \mathrm{O}_{\mathrm{III}}$ and $\mathrm{O}_{\mathrm{IV}}$, respectively. For other atoms of the same molecule maximum displacements are $0.35,0.3,0.44$ and $0.45 \AA$, whereas the corresponding values for atoms of neighboring molecules are $0.23,0.29,0.32$ and $0.31 \AA$.

In order to calculate the vibrational modes of these impurity configurations we constructed the dynamical matrix including the degrees of freedom associated with the $\mathrm{O}$ atoms and their nearest $\mathrm{C}$ atoms. It should be noted that Figures depict only the molecule or molecules that accommodate the impurities, even though the calculations of the vibrational modes take into account the complete crystalline environment with all the surrounding pentacene molecules.

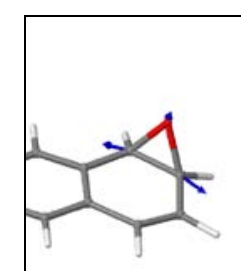

(a)

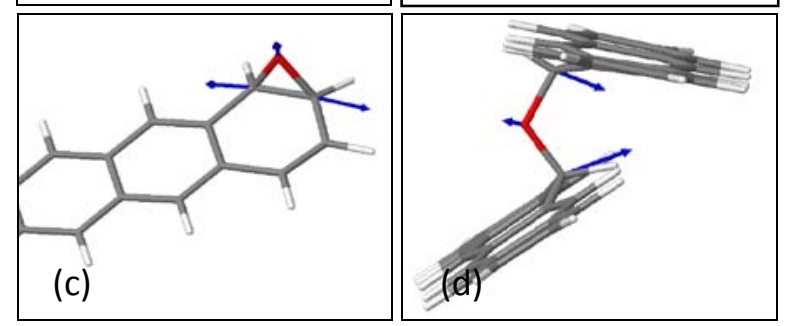

Figure 2. Selected vibrational modes of the 0-pair structures $\mathrm{O}_{\mathrm{I}}$ (a) and $\mathrm{O}_{\mathrm{II}}$ (b) and atomic 0 configurations $\mathrm{O}_{\mathrm{III}}$ (c) and $\mathrm{O}_{\mathrm{IV}}(\mathrm{d})$.

Vibrational modes of defects for structures $\mathrm{O}_{\text {II }}$, $\mathrm{O}_{\text {III, }}$ and $\mathrm{O}_{\text {IV }}$ are given in Table 1 . The type of vibrations for the highest energy modes of all structures are depicted in Figs. 2a-d. These modes have frequencies of $1385,1229,1389$, and $1181 \mathrm{~cm}^{-1}$, respectively. As expected, the frequencies calculated for the modes of structures $\mathrm{O}_{\mathrm{I}}$ (not shown) and $\mathrm{O}_{\mathrm{III}}$ are almost identical (within $10 \mathrm{~cm}^{-1}$ ), but this is not the case for $\mathrm{O}_{\text {II }}$ and $\mathrm{O}_{\mathrm{IV}}$. Likewise, the two atomic oxygen configurations, $\mathrm{O}_{\mathrm{III}}$ and $\mathrm{O}_{\mathrm{IV}}$ differ significantly in terms of frequencies. Those features suggest that experimental studies can distinguish not only the form of oxygenrelated impurity configurations, but also whether it is energetically favorable for oxygen in pentacene to appear in pairs or as individual impurities

TABLE 1: Vibrational modes for $\mathrm{O}_{2}$ into pentacene crystal, structures $0_{\text {III }}, 0_{\text {III }}$, and $0_{\text {IV }}$.

\begin{tabular}{|c|c|c|c|}
\hline mode & $\begin{array}{c}\mathbf{O}_{\text {II }} \\
\text { Freq. }\left(\mathbf{c m}^{-1} \mathbf{)}\right.\end{array}$ & $\begin{array}{c}\mathbf{O}_{\text {III }} \\
\text { Freq. }\end{array}$ & $\begin{array}{c}\left.\mathbf{O}_{\text {IV }} \mathbf{- 1}\right) \\
\text { Freq. }\end{array}$ \\
\hline $\mathbf{1}$ & 1229 & 1389 & 1181 \\
\hline $\mathbf{2}$ & 1147 & 1198 & 1121 \\
\hline $\mathbf{3}$ & 1110 & 1072 & 1061 \\
\hline $\mathbf{4}$ & 1056 & 899 & 1026 \\
\hline $\mathbf{5}$ & 1043 & 860 & 951 \\
\hline $\mathbf{6}$ & 1014 & 656 & 855 \\
\hline $\mathbf{7}$ & 1005 & 438 & 587 \\
\hline $\mathbf{8}$ & 915 & 429 & 562 \\
\hline $\mathbf{9}$ & 884 & 370 & 377 \\
\hline
\end{tabular}

\section{$3.3 \mathrm{H}_{2} \mathrm{O}$-related impurities}

In the case of $\mathrm{H}_{2} \mathrm{O}$-related impurities, we considered two structures [10] wherein the water molecule stays intact (physisorbed). One between pentacene layers, which is the stablest $\left(\mathrm{W}_{\mathrm{I}}\right)$ and another where $\mathrm{H}_{2} \mathrm{O}$ is between adjacent pentacene molecules in the same layer $\left(\mathrm{W}_{\mathrm{II}}\right)$. For the latter case the formation energy rises by $0.5 \mathrm{eV}$.

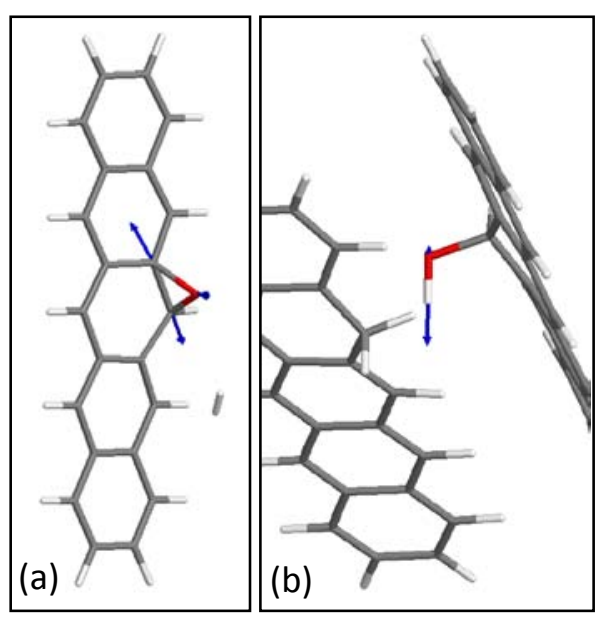


Figure 3. Vibrational modes of chemisorbed $\mathrm{H}_{2} \mathrm{O}$ impurities: (a) forming $\mathrm{COC}$ bond and $\mathrm{H}_{2}$, (b) forming $\mathrm{COH}$ bond and $\mathrm{CH}_{2}$ group.

The frequencies of the vibration modes are given in Table 2 . We are noticing a reduction of the frequencies for the stretching modes when $\mathrm{H}_{2} \mathrm{O}$ molecule is between molecules and a slight increase of the frequency for the bending mode. These small differences can thus clarify whether water molecules reside inside pentacene layers or between the layers in a particular experiment. Both these possibilities have been reported in previous studies $[9,24]$.

TABLE 2: Normal modes for a physisorbed $\mathrm{H}_{2} \mathrm{O}$ molecule in a pentacene crystal.

\begin{tabular}{|c|c|c|}
\hline Mode & $\begin{array}{c}\mathrm{H}_{2} \mathrm{O} \text { between } \\
\text { layers } \\
\text { Freq. }\left(\mathrm{cm}^{-1}\right)\end{array}$ & $\begin{array}{c}\mathrm{H}_{2} \mathrm{O} \text { between } \\
\text { molecules } \\
\text { Freq. }\left(\mathrm{cm}^{-1}\right)\end{array}$ \\
\hline $\begin{array}{c}\text { asymmetric } \\
\text { stretch }\end{array}$ & 3747 & 3659 \\
\hline $\begin{array}{l}\text { symmetric } \\
\text { stretch }\end{array}$ & 3564 & 3548 \\
\hline Bending & 1466 & 1474 \\
\hline
\end{tabular}

Next the case of two chemisorbed configurations for $\mathrm{H}_{2} \mathrm{O}$ impurities was studied. First, a water molecule dissociates into a COC group and $\mathrm{H}_{2}$ (Fig. 3a, $\mathrm{W}_{\text {III }}$ ) while for the second the dissociation leads to a $\mathrm{COH}$ and a $\mathrm{CH}_{2}$ group (Fig. $3 \mathrm{~b}, \mathrm{~W}_{\text {IV }}$ ). Compared to the most stable configuration WI, these chemisorbed structures have energies that are higher by 1.2 and $3.1 \mathrm{eV}$, respectively. They are thus metastable that can exist only under non-equilibrium conditions, perhaps during synthesis. The results for the vibrational modes for the COC group of structure $\mathrm{W}_{\mathrm{III}}$ and the $\mathrm{CH}_{2}$ group of $\mathrm{W}_{\mathrm{IV}}$ are presented in Table 3.

TABLE 3: Vibrational modes for chemisorbed $\mathrm{H}_{2} \mathrm{O}$ impurities in pentacene crystal structures

\begin{tabular}{|c|c|c|c|}
\hline mode & $\begin{array}{l}\text { COC in } W_{\text {III }} \\
\text { Freq. }\left(\mathrm{cm}^{-1}\right)\end{array}$ & $\begin{array}{l}\mathrm{CH}_{2} \text { in } \mathrm{W}_{\mathrm{IV}} \\
\text { Freq. }\left(\mathrm{cm}^{-1}\right)\end{array}$ & $\begin{array}{c}\mathrm{CH}_{2} \\
\text { Freq. }\left(\mathrm{cm}^{-1}\right)\end{array}$ \\
\hline 1 & 1319 & 2969 & 2936 \\
\hline 2 & 1173 & 2864 & 2865 \\
\hline 3 & 1046 & 1317 & 1322 \\
\hline 4 & 908 & 1267 & 1264 \\
\hline 5 & 764 & 1126 & 1121 \\
\hline
\end{tabular}

\begin{tabular}{|l|l|l|l|}
\hline $\mathbf{6}$ & 643 & 881 & 871 \\
\hline $\mathbf{7}$ & 441 & 836 & 790 \\
\hline $\mathbf{8}$ & 434 & 730 & 737 \\
\cline { 1 - 2 } $\mathbf{9}$ & 363 & \multicolumn{2}{|l}{} \\
\cline { 1 - 2 }
\end{tabular}

As can be deduced from a comparison between the results of Tables 2 and 3, the frequencies of the $\mathrm{W}_{\text {III }}$ modes are smaller from the corresponding values of the eigenvalues for the COC group of the $\mathrm{O}_{\mathrm{I}}$ configuration. This decrease is associated with the fact that the COC group occupies different sites in the two cases. In particular, the epoxy structure is located at the center ring in the $\mathrm{W}_{\mathrm{III}}$ case, while for $\mathrm{O}_{\mathrm{I}}$ it is found at the edge of the molecule.

Finally, we discuss the vibrational modes of an $\mathrm{H}$ atom that is absorbed in the form of $\mathrm{CH}_{2}$ unit, as shown in Fig. 4. Such H-related defects are known to add levels in the gap $[10,11,24]$ and thus are crucial for transport properties of pentacene.

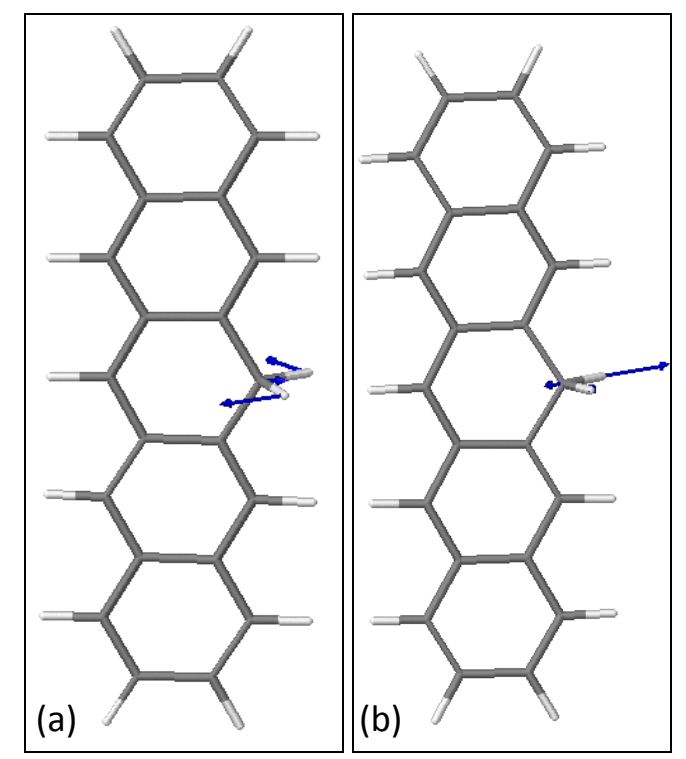

Figure 4. Bending mode of $\mathrm{CH}_{2}$ in pentacene crystal (a) and $\mathrm{CH}$ stretching mode of the $\mathrm{CH}_{2}$ group (b).

The eigenvalues of this impurity structure are included in Table 3 and they are, naturally, similar to the frequencies obtained for the $\mathrm{CH}_{2}$ group of the structure $\mathrm{W}_{\mathrm{IV}}$. For example, the $\mathrm{CH}_{2}$ bending mode for the $\mathrm{H}$ ad-atom structure, shown in Fig. 4a, has a frequency of $1322 \mathrm{~cm}^{-1}$ while for $\mathrm{W}_{\mathrm{IV}}$ the same mode has $1317 \mathrm{~cm}^{-1}$. Frequencies of the $\mathrm{CH}$ stretching 
modes for both this structure (Fig. 4b) and $\mathrm{W}_{\mathrm{IV}}$, are calculated 2936, 2969 and 2865, 2864 $\mathrm{cm}^{-1}$ (Table 3). Those are found to be lower than in pristine pentacene $\left(>3040 \mathrm{~cm}^{-1}\right)$.

As noted above, comparison between theoretical values for vibrational frequencies and pertinent experimental data can help identify, the atomic scale details of impurity configurations. For example, several 0-related modes $\left(1072,884,860,855,656,370,377 \mathrm{~cm}^{-}\right.$ 1) lie outside the intrinsic vibrational bands of pentacene [16] and may thus be detected in IR or Raman spectroscopy experiments. Likewise, there are $\mathrm{H}_{2} \mathrm{O}$-related modes (1267, $881,363 \mathrm{~cm}^{-1}$ ) which do not overlap with the modes of the host pentacene crystal.

\section{Summary}

In summary, we have calculated the vibrational modes of pristine pentacene and pentacene crystals with hydrogen, oxygen and water-related impurities. Variations in the position and structural form of the impurities give rise to differences in vibrational frequencies and can enable the characterization of these defects in pentacene.

The calculations used resources of the EGEE and HellasGrid infrastructure.

\section{References}

[1] D. Knipp, J. Appl. Phys. 101044504 (2007).

[2] Z. Zhu, Applied Phys. Lett. 814643 (2002).

[3] M. Rusu, Appl. Phys. Lett. 90153511 (2007).

[4] O. Mitrofanov, Phys. Rev. Lett. 97 166601 (2006).

[5] Y.S. Yang, Appl. Phys. Lett. 801595 (2002).

[6] A. Maliakal, Chem. Mat. 164980 (2004).

[7] C. Lee, Phys. Rev. B 4910572 (1994).

[8] T. Matsushima, Appl. Phys. Lett. 91 103505 (2007).
[9] O.D. Jurchescu, , Applied Physics Letters 87052102 (2005).

[10] L. Tsetseris, Phys. Rev. B 75153202 (2007).

[11] J. Northrup, Phys. Rev. B 68041202 (2003).

[12] L. Tsetseris, Phys. Rev. B 78115205 (2008).

[13] L. Tsetseris, Org. Electron. 10333 (2009).

[14] L. Tsetseris, Phys. Rev. B 82045201 (2010).

[15] H. Cheng, Org. Electron. 10289 (2009).

[16] Y. Yamakita, J. Chem. Phys. 126064904 (2007).

[17] S.R. Langhoff, J.l Phys. Chem. 1002819 (1996).

[18] R. He, Appl. Phys. Lett. 94223310 (2009).

[19] G. Kresse, Phys. Rev. B, Condensed Matter 5411169 (1996).

[20] D. Vanderbilt, Phys. Rev. B 417892 (1990).

[21] J. Perdew, Phys. Rev. B 235048 (1981).

[22] R. Campbell, Acta Cryst. 14705 (1961).

[23] R. Campbell, Acta Cryst. 15289 (1962).

[24] K. Lee, Surf. Sci. 6033445 (2009).

[25] D. Lang, Phys. Rev. Lett. 93076601 (2004). 